\title{
Research on the Management Innovation of Master Student's Financial Aid Under the New Situation
}

\begin{abstract}
Wei $\mathrm{Lu}^{*}$
Shanghai University of Political Science and Law, Personnel Division, Shanghai, China

*Corresponding author. Email: tengkun999@163.com

ABSTRACT

In recent years, the number of postgraduate enrollment and the proportion of professional masters in China has been increasing, so as to the overall level of tuition. In developed countries, the tuition of postgraduates has also risen gradually, and countries have made efforts to increase financial aid. Under this new situation, various problems have been exposed that the current funding for master's students is not taken seriously, the six existing funding methods cannot meet actual needs and the source of funding is relatively single. In response to these problems, the funding for master's students can be placed in a more important position in the future. Attracting private funds into the funding of master's students, and combining it with quality training, in addition, making policy-based student loans be the main means of funding for master's students. 10-point font. Do not cite references in the abstract. Please do not place or cite tables and figures in the abstract either.
\end{abstract}

Keywords: Postgraduate student, Financial aid, Student loan, Grant.

\section{新形势下硕士研究生资助制度管理创新研究}

$$
\text { 卢伟* }
$$

上海政法学院，人事处，上海，中国

*通讯作者. 邮箱: tengkun999@163.com

\section{中文摘要}

近年来我国硕士研究生招生人数不断增加, 专业硕士比重不断加大, 学费水平整体提高, 发达国家硕士研究生 学费也日渐上扬, 各国加大了经济资助。在这样的新形势下当前的硕士生资助存在着不受重视, 现有的六种资 助手段不能满足实际需要, 资助资金来源比较单一的问题, 今后可以把硕士生资助放到更加重要的位置, 吸引 民间资金进入硕士生资助，并和素质培养结合起来，同时政策性助学贷款应成为硕士生资助的主要手段。

关键词: 硕士研究生, 资助, 助学贷款, 助学金

\section{1. 引言}

自从上世纪70年代末恢复高考, 90年代大学开始 大规模收取学费以来, 对困难学生的资助就成为高等 教育的一个热点问题, 受到教育研究界乃至全社会的 关注, 在这方面形成了全面的、丰富的成果, 为资助 政策的建立和改进提供了源源不断的理论支持。经过
数十年来的政策发展, 我国大陆地区当前已经形成了 “奖、贷、助、勤、补、减”六个资助手段有机构成的 资助体系, 涵盖了中职生、本科生、硕士生、博士生 等多个层次的群体, 发挥着巨大的作用。近年来, 随 着经济和社会形势的发展，学历贬值倾向不断增强， 硕士生日渐成为就业的中坚力量, 从事着企业、机关、 
事业单位具有较高技术含量的工作，在经济发展和社 会进步中承担着重要的人力资本的支持作用, 而当前 的硕士生资助在新的国内国际形势下还存在着一些 不足，这阻碍了很多优秀但是家庭经济状况困难学生 的考研倾向, 影响着人力资本顺利的积累, 进而影响 着经济发展和社会进步, 因此, 对这个问题进行分析, 是有着一定的政策意义和社会效应的。

\section{2. 关键概念的界定}

本文提到的资助仅指经济资助，不涵盖其他方面 如社会资本和心理资本等领域的资助。本文提到的硕 士研究生仅指全日制硕士研究生 (以下简称硕士生), 不包括在职的硕士研究生, 因为在职硕士生这部分群 体基本都有工作，有一定的经济收入，客观上对资助 的需求不大。本文也没有把博士研究生纳入研究范围, 因为博士研究生中全日制博士生基本全免学费, 且针 对这个群体的国家助学金有较大提高, 学校、学院和 导师也都有金额不等的一定资助; 在职博士生基本都 有工作, 有一定的经济收入, 需要资助的迫切性不大, 因此整体而言博士生资助已经在较大程度上解决较 好, 同时博士生相对硕士生人数较少, 硕士生这个群 体规模更大, 是整个研究生的主体, 无论从招生、培 养和就业来看, 对社会的辐射面也更广, 更值得研究。

\section{3. 硕士生资助面临的新的国内和国际形势}

\section{1. 硕士生资助面临的国内形势变化}

硕士生资助面临的国内形势变化主要体现在两个 方面: 一是硕士生招生人数不断增加; 二是硕士生招 生结构不断变化, 学费水平整体上扬。

近年来, 随着大学本科毕业人数的不断增加, 经 济下行压力增大, 给本科生就业带来了一定的影响, 本科毕业生不太容易找到满意的工作, 只好进一步深 造, 这是硕士生人数不断攀升的“推”的因素, 与此同 时, 随着经济和社会的进步, 用人单位对人才的要求 也在不断提高, 很多工作岗位本科生已经不能适任, 硕士生成了很多工作岗位的必要条件, 这是硕士生人 数不断攀升的“拉”的因素, “推”和“拉”两方面的因素 导致硕士生报考和招生人数不断增加, 2017年硕士生 招生人数为 72.22 万人, 而在校硕士生人数已经达到 227.76 万人, 这其中相当一部分比例的硕士生来自于 经济困难家庭, 对硕士生资助工作提出了更高的要求。

另外, 现行的硕士生按照培养目标不同主要分为 两大类, 学术硕士和专业硕士, 学术硕士未来还可以 就读博士, 着眼于这个目标, 其培养方向偏学术研究, 课程涵盖理论学习和研究方法; 专业硕士则主要瞄准 就业, 培养方向偏实务, 注重校外实务界导师的作用。 学术硕士学费相对较低, 一般在每年1-2万元左右, 而专业硕士的学费由于培养成本的原因, 以及考虑到 未来收益较高, 其学费定价是比较高的, 以几种常见 的、报考较多的专业硕士为例, 工商管理硕士 (MBA) 学费一般在每年 $8-10$ 万元左右, 金融硕士学费一般在
每年3-8万元左右, 会计硕士一般在每年 2-7万左右, 法律硕士学费一般在每年1.5-3万元左右 (根据学校地 理位置、学校档次、学科水平不同有一定差异)，而 现在定位为解决硕士生学费的国家助学贷款, 其每年 面向硕士生的贷款额度是 12000 元, 这很大程度上满 足不了专业硕士的学费需求, 客观上会降低考生的报 考意愿, 影响人力资本的进一步积累, 国外已有的研 究也验证了这一点, 如收入水平的不同以及资助会影 响就学率。[1]

\section{2. 硕士生资助面临的国际形势变化}

硕士生资助面临的国际形势变化主要表现在：世 界主要国家纷纷提高（收取）学费, 并加大了对硕士 生的资助。

近年来，世界主要国家由于多种原因的影响，纷 纷提高或开始收取高等教育阶段的学费。美国由于受 次贷危机的影响，各州政府财政压力加大，被迫减少 了对州所属公立大学的拨款, 为保证高等教育的质量, 州立大学只能提高学费来弥补办学经费的不足, 尤其 是时间短、见效快、外国学生就读多的硕士项目, 能 够给大学带来更快捷方便的资金补助, 同时还不会很 大程度上激起本国学生的不满情绪, 更是提高学费的 首要选择; 与此同时, 私立大学则由于金融危机的影 响, 其大学所属基金会的投资贬值严重, 一定程度上 影响了办学, 同时公立大学提高学费的做法对其是个 刺激, 树立了一个参照的模板, 也纷纷提高了学费, 尤其是硕士生学费。英国这种早就开始收取大学学费 的欧洲海岛国家的学费水平也在不断上扬, 以弥补政 府财政经费的不足, 提高学费的举动甚至还激起了大 学生上街游行, 以抗议不断上涨的大学学费, 同样, 非欧盟的外国学生就读较多的硕士项目也是提高学 费的重灾区。法国和德国这种传统的、高等教育接近 免费的欧洲大陆国家近年来也有收取学费的倾向, 2018年11月法国宣布从2019年9月起，将会对在法国 公立院校留学的非欧盟学生提高注册费 (类似学费), 本科生提高到每年2770欧元, 硕士和博士生提高到每 年3770欧元, 硕士生的学费提高幅度高达 10 倍之多, 未来对本国学生的收费是否提高还不明朗。

大学学费的提高必然要求资助力度的加大, 以安 抚学生的情绪和解决他们就读大学的经济需求, 以美 国为例, 其最主要的学生资助手段——助学贷款总量 不断攀升, 迄今为止已经达到 1.5 万亿美元。法国在提 高学费的同时, 也提出了增加资助手段的措施。

\section{4. 现有的硕士生资助手段已不能适应新形势 的要求}

\section{1. 硕士生资助相对于博士生和本科生资助问 题更大}

本硕博三个阶段的资助体系中, 全日制博士生 (出 于培养质量的考虑，目前博士生招生对在职博士生限 
制很严, 主要招收的是全日制博士生）基本上全免学 费, 同时政府、学校和导师还给予一定的补助, 用于 其生活费开支。本科生的学费普遍较低, 基本维持在 每年3000-10000元的水平上, 现行面向本科生的国家 助学贷款额度是每年 8000 元, 大体上能够满足学费需 求, 解决了这个最大的问题。针对本科生的国家助学 金每年2000-3000元，虽然存在着不能满足学生生活 费需求的问题，但可以在一定程度上缓解。

硕士生这个群体中，专业学位硕士生没有可以足 够解决学费的资助手段, 而专业学位硕士生占全部硕 士生的比重越来越大, 2017年专业学位硕士生招生规 模已经超过学术硕士生, 达到当年硕士生招生总数的 $56 \%$, 未来这个趋势还将进一步加大。另外, 无论是 专业学位硕士生, 还是学术学位硕士生都没有可以足 够解决生活费的资助手段, 国外也有研究涉及到贫困 生的生活费容易被资助忽略的问题。[2]而硕士生年龄 相对本科生已经不小, 再继续向父母要钱已经不太合 适, 因此很多硕士生在就学阶段出去打工赚取一定的 收入来支付生费费和弥补一定比例的学费, 这在很大 程度上又影响了学业, 使得很多导师对硕士生不满, 影响了师生之间的关系, 进而影响了硕士生的培养。

\section{2. 现有的六种资助手段不能满足硕士生的实 际需要}

现有的硕士生资助体系包括奖、贷、助、勤、补、 减六个方面。先来看奖学金方面, 硕士生的国家奖学 金全国范围内只有 3.5 万名额, 而2018年在校硕士生 234.17 万人, 能够获得国家奖学金的硕士生仅占硕士 生总数的 $1.5 \%$ 左右, 覆盖范围比较小。除了国家奖学 金之外, 学校还有一部分面向硕士的奖学金, 但覆盖 范围和额度也显然是不能满足绝大部分硕士生尤其 是专业学位硕士生的资助需求的。实际上, 奖学金主 要是为了激励硕士生好好学习及投入学术研究, 本身 也不是设计用来资助困难学生的。国家助学贷款方面, 硕士生只有每年12000元的助学贷款额度, 如前文所 述, 仅够覆盖学术硕士的学费, 很难覆盖很多专业学 位硕士生的学费, 而未来的发展趋势是专业硕士的招 生比重将会在整个硕士招生中越来越高。用来设计解 决生活费的助学金方面, 额度明显不足, 现行的规定 是全日制硕士生每年助学金为6000元, 用于维持生活 支出, 平均到每个月只有 500 元, 在内陆省份的省会 城市都明显不足, 更不用说沿海一线城市了, 而有硕 士点的大学主要都位于省会城市及更繁华、物价水平 更高的沿海一线、二线城市。勤工助学目前规定每月 最多不超过 40 小时 (以免影响学生的学习), 每小时 实行不低于 12 元的标准, 如果做足 40 小时的话每月可 获得约 480 元的资助, 但在实际操作中很少有做足 40 个小时的, 由于贫困生人数较多, 勤工助学的机会和 资金需要平均分配给每个贫困生, 使得大部分贫困生 的勤工助学时间达不到每月 40 小时, 对于硕士生来说, 由于每小时 12 元的标准过低 (远远低于硕士生在校外 兼职的时薪），因此硕士生更多地是在校外兼职以获
取一定的收入来弥补自己的生活费支出, 这又在很大 程度上影响了专业知识的学习。困难补助和减免学费 不属于主要的资助手段, 基本属于补充式的补助, 难 以发挥主要的资助作用, 无论广度和深度方面都是不 足以满足硕士生的实际需要的。

\section{3. 硕士生资助的资金来源单一}

目前硕士生资助的资金主要以国家助学贷款和国 家助学金为主, 资助资金主要来源于政府部门（提供 国家助学金) 和国有银行体系（提供国家助学贷款） 以及高校自身的资金（提供学校奖学金等），缺乏筹 集硕士生资助资金的多种渠道，如在发达国家比较普 遍的，来自于企业、个人和慈善基金会的捐赠资金, 这也是目前资助资金不足的主要原因之一。个别名校 由于自身基础较好, 成功校友较多, 吸引教育捐赠方 面做得不错, 这些吸引的教育捐赠很多投到了学生资 助领域, 但全国大部分高校, 尤其是中小型地方高校 在吸引教育捐赠方面都还不太理想, 今后这方面还很 值得进一步拓展。

随着未来硕士生的进一步扩招, 专业硕士招生比 重的不断加大, 硕士生的平均学费将会继续维持在较 高水平, 并有可能继续上扬, 现行的硕士生资助体系 是无法充分满足硕士生完成学业, 积累人力资本, 成 为经济和社会发展所需要的人才的需要的。

\section{5. 新形势下硕士生资助的改进对策}

\section{1. 把硕士生资助放到更加重要的地位}

前文已经述及, 博士生由于人数较少, 且基本没 有学费这个最大的求学负担, 学校和导师一般还能给 予一定的资助, 本科生学费尚且保持在一个较为合理 的水平上, 现有的国家助学贷款额度能够完全覆盖, 因此博士生和本科生的资助大体上运行良好。实际上, 本科生资助重心主要在政府和国有银行体系, 博士生 的资助重心在政府和导师，而硕士生资助则没有一个 资助重心，无论是政府、国有银行体系还是导师，都 无法从其获得足够的资助资金。学费方面国有银行体 系的国家助学贷款不能完全覆盖专业硕士的学费, 导 师资助方面, 由于硕士生协助导师从事科学研究方面 的能力不如博士生, 发挥不出较大作用, 因此从导师 那里获得的资助相对较少, 尤其是培养目标本来就不 是学术研究, 而是面向社会就业的专业硕士而言, 对 导师科学研究的协助更少, 从导师那里获得的资助更 是微乎其微。随着经济的发展, 社会的进步, 高等教 育的学历贬值化倾向越来越严重, 过去本科生就能从 事的岗位现在基本都需要硕士生来从事, 未来的就业 中坚是硕士生 (这个就业中坚并不是指就业的人数比 重, 而是从就业岗位的重要性角度而言）, 与硕士生 相比, 本科生人力资本含量略显不足, 尤其是在经济 社会形势飞速发展的背景下, 博士生则侧重研究, 大 部分就业岗位并不需要很强的研究能力, 否则也是人 才和学历的过度消费, 因此, 在一个较长的时期内, 
硕士生都将是就业的主力，更应该把硕士生资助放到 更重要的地位, 设计出比较科学合理的、专门针对硕 士生资助的政策来，适应硕士生不断增加招生，专业 硕士比重不断加大, 学费不断提高的新形势, 国外也 有研究验证了政府资助的重要性[3]。

\section{2. 吸引民间资金参与硕士生资助，并和素质 培养结合起来}

硕士生资助的资金来源仅靠原有的政府资金和国 有银行体系的国家助学贷款资金是远远不够的，除了 这些公共部门的资金来源以外, 今后更需要大力拓宽 资金来源的渠道，尤其是吸引民间资金参与到硕士生 资助的过程中来，包括采取多种措施吸引企业、个人 和慈善基金会的捐赠。政府可以推出一些激励民间资 金捐赠硕士生资助的公共财政扶持政策，如企业所得 税和个人所得税的税收减免, 以及针对硕士生资助捐 赠的财政配比政策，即对民间资金捐赠硕士生资助的， 政府按照捐赠金额的一定比例进行配比，根据世界各 国的成熟政策经验，这个财政配比比例不一定是一比 一, 可能大于一比一, 也可能小于一比一, 要根据受 赠高校的具体情况和政府扶持力度来合理确定, 财政 配比经费也算在捐赠人的名下; 除了公共财政扶持政 策以外, 政府和高校还可以推出精神激励政策, 如在 新闻媒体上登载捐赠信息, 宏扬捐赠文化, 在全社会 形成一个捐赠的氛围, 精神激励政策和公共财政扶持 政策配合起来，效果往往更好。

除了政府可以采取的相应措施以外, 高校也可以 结合自身的情况采取一些吸引民间资金参与硕士生 资助的举措, 如商学院联系校友企业为硕士生提供带 薪实习机会等, 法学院联系律所或其他法律服务机构 包括公证处、法律翻译公司等为硕士生提供法律带薪 实习机会等, 这样不仅起到了对硕士生进行经济资助 的目的, 还能帮助硕士生联系实践, 尽早熟悉就业单 位以及社会, 提高自己的专业素质, 并培养他们对资 助资金提供方、实习企业和社会的感恩心态, 以便未 来更好地回报社会，实现综合的育人效应。

\section{3. 应把政策性助学贷款设定为硕士生资助的 主要手段}

当前硕士生资助最大的问题主要是占硕士生主体 的专业硕士学费得不到有效的资助, 这个问题解决不 好, 整个硕士生资助体系就没有稳固的基础。参考世 界各国的经验, 结合中国的实际情况, 笔者认为: 政 策性助学贷款 (不以盈利为目的的贷款) 应成为硕士 生资助的主要手段, 应提高额度, 根据硕士专业学费 的不同充分满足需要, 商业性助学贷款 (可以适当盈 利的贷款）应成为硕士生资助的补充, 这可能是比较 合适的制度安排。

一般认为, 基于公共产品理论, 高等教育是半公 共产品, 需要混合提供, 即政府以拨付大学建设和运 营经费、提供科研经费等方式承担一部分高等教育的
成本, 个人也要以学费的方式负担一部分高等教育的 成本。与硕士教育相比, 本科教育和博士教育这两种 半公共产品更加接近公共产品一些, 而硕士教育这种 半公共产品则更加接近私人产品一些, 因此在硕士生 资助中, 有借有还的助学贷款所占的比重应该更高一 些, 无需归还的助学金所占的比重应该低一些。具体 而言, 应提高现行的针对硕士生的国家助学贷款的额 度, 根据不同专业学费的水平全额保障, 可以考虑推 行基本额度加上专业调节额度的做法来确定不同硕 士专业的贷款额度, 基本额度可以设定为一般性的学 术硕士的学费水平，专业调节额度则根据不同的专业 硕士相对于学术硕士学费的差额来确定。一般而言, 不同硕士专业的学费是和未来工作的收入成正比的, 学费越高, 未来工作后的收入越高, 否则该专业的招 生也会受影响，这个专业就会被市场机制所淘汰，而 工作后的收入越高, 则国家助学贷款的还款能力也越 强, 因此从还款能力角度考虑, 提高国家助学贷款额 度不会很大程度上带来还款坏账的问题，如果再通过 个人信用系统来保障还款意愿，那么提高硕士生国家 助学贷款额度，基本上不会产生太多的坏账问题。

随着高等教育发展进入大众教育和普及教育的新 阶段, 结合中国这种重视教育的文化传统, 可以想见, 未来硕士生可能成为父母对孩子最终学历的普遍期 望, 硕士生的招生还将进一步加大, 这将对硕士生的 资助提出更高的要求，现在硕士生资助政策正处于过 渡期, 应尽早完成这个资助政策的过渡, 为更好地激 励学生报考硕士做好政策准备, 为经济发展、社会进 步和中华民族的伟大复兴提供源源不断的人力资源 支持。

\section{REFERENCES}

[1] Rong Chen, Stephen L. DesJardins, Exploring the Effects of Financial Aid on the Gap in Student Dropout Risks by Income Level, Research in Higher Education, vol.49, 2008, pp.1-18. DOI: https://doi.org/ 10.1007/s11162-007-9060-9

[2] R. Kelchena, S. Goldrick-Rabb, B. Hosch, The Costs of College Attendance: Examining Variation and Consistency in Institutional Living Cost Allowances, The Journal of Higher Education, vol. 88, no. 6, 2017, pp.947-971.DOI:http://dx.doi.org/10.1080/0022154 6.2016 .1272092

[3] R.K.Toutkoushian, M. Najeeb Shafiq, A Conceptual Analysis of State Support for Higher Education: Appropriations Versus Need-Based Financial Aid, Research in Higher Education, vol.51, 2010, pp. 40-64. DOI: https://doi.org/ $10.1007 /$ s11162-009-9148-5 